\title{
Unit of Osmotic Concentration
}

National Cancer Institute

\section{Source}

National Cancer Institute. Unit of Osmotic Concentration. NCI Thesaurus. Code C67425.

A unit for measurement of concentration of osmotically active particles expressed as a

number of osmoles of solute per liter of solution. 